\title{
Gestão de competências e qualificação profissional no segmento da alimentação coletiva
}

\section{$(10$}

\author{
Management of competences and \\ professional qualification in \\ the food service segment
}

Fabiana Bom KRAEMER ${ }^{1}$

Odaléia Barbosa de AGUIAR ${ }^{1}$

\section{RE S U M O}

\section{Objetivo}

Identificar a qualificação e a competência dos trabalhadores do segmento de alimentação coletiva.

\section{Métodos}

O recorte deste estudo qualitativo privilegiou o grupo de cozinheiros e nutricionistas como sujeitos sociais que detêm os atributos que a investigação pretendeu revelar. O trabalho de campo foi realizado a partir de entrevistas individuais semi-estruturadas, em cozinhas industriais administradas por terceiros ou auto-gestão, no Estado do Rio de Janeiro.

\section{Resultados}

O estudo evidenciou que a qualificação do grupo de cozinheiros se dá pelo aprender a fazer, isto é, a experiência em cozinhas habilita ao desenvolvimento de atividades de preparos de alimentos, levando, em média, de três a quatro anos de trabalho no segmento para ascender ao posto de cozinheiro. O nutricionista percebe a competência dos trabalhadores no seu potencial de liderança. Para os cozinheiros esta pode ser reconhecida na sua capacidade de liderar, satisfazer o cliente, acompanhar os avanços tecnológicos, atualizar-se no que se refere aos cardápios e considerar o custo nas preparações.

\section{Conclusão}

Aponta-se a necessidade da normalização das competências e de introdução de um sistema de certificação técnica, com vistas ao sucesso da gestão de pessoas.

Termos de indexação: Alimentação coletiva. Gestão de pessoal. Serviços de alimentação.

\footnotetext{
1 Universidade do Estado do Rio de Janeiro, Instituto de Nutrição, Departamento de Nutrição Aplicada. R. São Francisco Xavier, 524, sala 13026, Bl D, Maracanã, 20550-013, Rio de Janeiro, RJ, Brasil. Correspondência para/Correspondence to: F.B. FRAEMER. E-mails: <fabiana_kraemer@hotmail.com>; <fkraemer@uerj.br>.
} 
610 F.B. KRAEMER \& O.B. AGUIAR

\section{A B S T R A C T}

\section{Objective}

The objective was to identify the qualifications and competences of workers from the food service segment.

\section{Methods}

This qualitative study investigated a group of cooks and nutritionists in order to determine their attributes. Semi-structured individual interviews were administered by third parties or by self in the State of Rio de Janeiro.

\section{Results}

This study evidenced that the group of cooks acquire qualification through practice, that is, by working in a kitchen. It takes three to four years working in the segment for them to be promoted to cooks. The nutritionist perceives the competence of the workers in their potential leadership. For cooks, this can be seen in their ability to lead, satisfy the customer, follow technological advances, stay up to date regarding the menus and bear in mind the cost of preparations.

\section{Conclusion}

Normalization of the competences and introduction of a technical certification system are necessary to successfully manage people.

Indexing terms: Collective Feeding. Personnel management. Food services.

\section{N T R O D U Ç Ã O}

A qualificação profissional é usualmente definida pelo conjunto de habilidades e requisitos que compõem o desenho do cargo ou pelos saberes que identificam o indivíduo com as condições necessárias ao desempenho de suas funções. Está ligada ao sistema de educação formal e, também, aos sistemas de qualificação específicos, oferecidos pelas empresas'.

Segundo uma abordagem substancialista, parte-se da qualidade e da complexidade das tarefas para chegar aos atributos necessários aos trabalhadores; adotando-se uma abordagem relativista observam-se a relação entre capital e trabalho e os fatores sócio-culturais que influenciam o julgamento e a classificação do indivíduo, feitos pela sociedade ${ }^{2}$.

Na prática, a qualificação dos trabalhadores é complementada pelo conjunto de competências desenvolvidas no trabalho, articulando vários saberes, que seriam advindos de múltiplas esferas $^{3}$. A passagem da qualificação à competência significa um deslocamento dos conhecimentos validados pelos diplomas em direção aos conhecimentos reais dos trabalhadores, associados a uma interrogação sobre o sentido desses conhecimentos e da qualificação no âmbito da gestão do trabalho ${ }^{4}$.

Competência, portanto, deve corresponder a tudo o que se espera de um trabalhador no desempenho do trabalho. Deve incluir capacidade técnica de acordo com um padrão preestabelecido e um conjunto de qualidades ligadas a atitudes, como: iniciativa, criatividade, senso de oportunidade, traços colaborativos para o trabalho coletivo, capacidade de decisão e aptidão para solucionar problemas ${ }^{5}$.

A adoção da gestão de pessoas, fundamentada em competências ou na qualificação profissional, se dá em um universo empresarial em transformação, impulsionado pelas inovações tecnológicas, direcionado por uma lógica liberal que enfatiza a flexibilização das atividades produtivas, a competitividade e a qualidade, atribuindo, exclusivamente ao indivíduo, a responsabilidade por sua competência e qualificação.

As empresas de concessão de alimentos se estabelecem no mercado de produção de refeições com serviços de baixo custo e um grande contingente de mão-de-obra não qualificada formalmente para o setor ${ }^{6}$. A aprendizagem ocorre em serviços, pois estes se caracterizam por trabaIhadores com habilidades facilmente disponíveis 
no mercado de trabalho, sujeitos a fácil reposição operacional e sem restrição ao grau de escolaridade. No segmento de alimentação coletiva estas características contribuem para o fenômeno da alta rotatividade e, conseqüentemente, dificuldade em obtenção da qualidade.

O segmento de alimentação coletiva se expande a partir da década de 70, atrelado à nova tecnologia de administrar as empresas - terceirização das atividades-meio ${ }^{7}$. Esta expansão demanda às empresas de serviços de alimentação, de forma inexorável, a busca permanente de competência e da qualificação do seu pessoal para que mantenham o diferencial competitivo no mercado e estejam aptas ao sucesso.

Os empregadores não apreenderam o prejuízo que impuseram ao aumento da produtividade e à qualidade, ao postergar o investimento em treinamento no ambiente de trabalho e o conseqüente ganho que poderiam usufruir com trabalhadores melhor qualificados.

O momento atual exige dos trabalhadores de alimentação coletiva, não somente preparar refeições, mas monitorar a segurança alimentar, habilitar-se em novas tecnologias, operar novos equipamentos, desenvolver seu potencial cognitivo para preencher as condições necessárias ao desempenho de suas funções e suas interações sociais entre sujeitos de diferentes mundos, culturas e práticas alimentares e sociais. Um novo tipo de trabalhador, capaz de compreender e participar de um ambiente no qual as decisões são mais complexas e as interações sociais, mais numerosas. Ademais, as noções de qualificação e competência abrangem manifestações cujos conteúdos não são universais, sendo pertinente o estudo de áreas específicas com recortes relativos a conteúdos teórico-práticos, frutos de experiências e trajetórias individuais, coletivas, situadas e datadas $^{8}$.

A importância de as empresas buscarem conhecer as competências que devam ser desenvolvidas, e a inexistência de estudos no segmento de alimentação coletiva nortearam o presente estudo a buscar compreender e identificar a quali- ficação e as competências que os trabalhadores de alimentação coletiva possuem e quais deverão desenvolver e/ou aperfeiçoar.

\section{MÉ TO D O S}

A pesquisa qualitativa busca compreender os fenômenos que estão sendo estudados a partir da perspectiva dos participantes, considerando todos os pontos de vista como importantes. A metodologia qualitativa foi escolhida porque permite investigar problemas poucos conhecidos, entender o fenômeno como um todo, na sua complexidade, e compreender a teia de relações sociais e culturais que se estabelecem no interior das organizações ${ }^{9}$.

Esta metodologia possibilitou trazer à tona informações subjetivas dos trabalhadores de alimentação coletiva em diferentes funções no processo de trabalho e nos ritos de mudanças de cargos que exigem o desenvolvimento de competências durante o seu desempenho profissional. A análise do conteúdo buscou ser eficaz, rigorosa e precisa na compreensão do discurso e aprofundar as características das falas, extraindo os momentos mais importantes.

O trabalho de campo foi realizado em quatro cozinhas industriais administradas por empresas de refeições coletivas (serviços de terceiros), e em uma administrada pela modalidade autogestão.

Participaram do estudo 8 nutricionistas e 17 cozinheiros (chefes de cozinha, cozinheiros líderes e cozinheiros) nos locais de trabalho. Estes foram considerados suficientes por permitir certa reincidência das informações. Minayo ${ }^{10}$ entende que, na sua homogeneidade fundamental relativa aos atributos, o conjunto de entrevistados possa ser diversificado, para possibilitar a apreensão de semelhanças e diferenças, e que a escolha do locus e do grupo de observação e informação contenha o conjunto das experiências e expressões que se pretendeu alcançar com a pesquisa.

Uma vez que a competência está associada à execução de tarefas complexas e que exigem 
uma atividade intelectual importante, o trabalhador competente não é, necessariamente, aquele que cria as técnicas, mas aquele que as utiliza adequadamente e está apto a adaptá-las às novas situações de trabalho ${ }^{5}$. Assim, a escolha do nutricionista e dos diferentes cargos de cozinheiro como grupo de estudo se deu pelo fato de estes estarem envolvidos nas atividades do processo de produções de refeições, o que prioriza os sujeitos sociais que detêm as qualificações e competências necessárias que a investigação pretendeu revelar.

A opinião do nutricionista foi relevante por ser este o chefe hierarquicamente superior a quem o cozinheiro deve se reportar, aquele que avalia o seu desempenho e é o principal formulador de opinião sobre a atuação desse trabalhador, assim como aquele que possibilita a ascensão ao cargo, confirmando a competência do indivíduo para a nova função.

Neste estudo, os cozinheiros dos serviços de alimentação coletiva foram tratados como sujeitos do seu trabalho, com os seus modos de pensar e agir cultural, organizacional ou político. O objetivo foi reconstruir as estratégias que formam as atitudes profissionais sobre os atributos de competências desenvolvidos pelos que ascendem aos cargos oferecidos no segmento de alimentação coletiva.

O estudo das trajetórias considerou a ocupação anterior ao ingresso no segmento da alimentação coletiva, o motivo pelo qual se optou pela inserção neste setor e, uma vez dentro do ramo da cozinha, como se deu a ascensão profissional até o cargo de cozinheiro.

Na definição das categorias analíticas deste estudo e, por conseguinte, o contorno das categorias empíricas, considerou-se a distinção feita por Minayo ${ }^{10}$.

As categorias analíticas definidas, em função da demanda que se apresentava, foram: processo de trabalho, qualificação profissional e competência.

A definição de categorias empíricas norteou a realização de uma entrevista semi- -estruturada, em que o entrevistador mantinha-se na escuta, intervindo com discretas interrogações de conteúdo ou com sugestões que estimulassem a expressão de questões que interessavam à pesquisa. As categorias empíricas definidas para o momento de coleta de informações foram:

- Identificação: nome; sexo; data de nascimento.

- Trajetória ocupacional: no que trabalhava antes de entrar no ramo da cozinha; qual o motivo que o levou a entrar na profissão; quanto tempo trabalha em cozinhas; quanto tempo está no cargo de cozinheiro; como foi o início do trabalho em cozinhas; contar um pouco a história; os primeiros cargos ocupados; os locais de trabalho.

- Qualificação e competência profissionais: escolaridade; se fez curso profissionalizante; se considera importante fazer curso profissionalizante; cursos de capacitação realizados, oferecidos pela empresa; o que considera ser um bom cozinheiro; se considera um bom cozinheiro; o que ganhou com o exercício da profissão.

- Situação de trabalho: faixa salarial; carga horária; com quantas pessoas trabalha diretamente; principais atividades realizadas no dia a dia do trabalho; quais as que ele gosta mais; por que; se gosta do que faz.

- Relações interpessoais no trabalho: se a relação com o nutricionista interfere ou colabora no trabalho; relacionamento com a equipe; principais problemas que enfrenta com a equipe.

As entrevistas realizadas com os nutricionistas preservaram a mesma estrutura que foi utilizada com os cozinheiros, com alterações nas questões relativas à trajetória ocupacional do nutricionista, pesquisando-se o ano de formatura, o tempo que atua na área de alimentação coletiva e o tempo de chefia. Na categoria qualificação e competência profissionais foram feitas as seguintes perguntas: o que seria um bom cozinheiro; se considera importante o cozinheiro ter um curso profissionalizante; se os cozinheiros da cozinha o possuíam; caso os cozinheiros não possuíssem, por 
que não eram estimulados a realizar. Quanto à categoria relações interpessoais, as questões versavam sobre os principais problemas enfrentados com os cozinheiros e se o nutricionista interfere e/ou colabora no trabalho dos cozinheiros.

As entrevistas com nutricionistas e cozinheiros, obtidas por meio de gravação em fita cassete, foram iniciadas após a assinatura do Termo de Consentimento Livre e Esclarecido. O projeto foi aprovado pela Comissão de Ética em Pesquisa do Hospital Universitário Pedro Ernesto (RJ), sob o protocolo $n^{\circ}$ 1544/CEP/HUPE.

Para a análise dos conteúdos das entrevistas foi diagramada uma matriz, com o auxílio do software Microsoft ${ }^{\circledR}$ Excel 2002, com as categorias centrais do estudo, em que as falas dos entrevistados eram registradas na íntegra. Esta etapa tinha como premissa possibilitar a análise temática. Os temas foram isolados das falas e deles se extraíam as partes utilizáveis, de acordo com o problema pesquisado, para permitir a comparação entre os sujeitos. Os temas foram classificados como principais e secundários. O primeiro define o conteúdo da parte analisada no texto e o segundo especifica diversos aspectos não considerados, incluídos no primeiro"11.

\section{RESULTADOSE DISCUSSÃO}

A sistematização dos resultados e a discussão, sintetizando questões que se articulam com os objetivos do estudo, encontram-se organizados de acordo com a construção analítica desenvolvida.

O grupo dos cozinheiros compreendeu indivíduos do sexo masculino, com idades entre 21 e 49 anos e com escolaridade variando entre 4 e 11 anos de estudo. Em média os cozinheiros atuam no segmento de alimentação coletiva há 10 anos (Desvio-padrão - DP=6) e exercem a função há 4 anos ( $D P=3)$. Os dados apontam também que, em média, os trabalhadores passaram um período mínimo de 4 anos em atividades nas cozinhas para incorporar técnicas de preparo de alimentos, o que possibilitaria a ascensão para o cargo de cozinheiro.

A jornada de trabalho foi de $44 \mathrm{~h}$ semanais, de segunda a sexta-feira ou de domingo a domingo, com uma folga semanal e uma renda que variou entre $R \$ 390,00$ e $R \$ 1.100,00$, semelhante ao descrito por Cavalli \& Salay ${ }^{12}$, em um estudo realizado com funcionários, sem distinção entre cargos, em restaurantes comerciais em São Paulo e Porto Alegre, onde a média de jornada de trabalho foi de 41,5 horas semanais e a faixa salarial de $R \$ 335,41$ a $R \$ 1.049,29$. No universo estudado constatou-se que no serviço autogestão os salários eram significativamente maiores representando, em média, $1 / 3$ a mais que nas empresas de concessões de refeições.

O preparo dos alimentos, a determinação junto com a nutricionista dos tipos de corte a serem utilizados no pré-preparo, a supervisão, a discussão de cardápios e a organização das tarefas da equipe foram as atividades identificadas pelos cozinheiros. Apenas um cozinheiro relatou não gostar das atividades que desempenha.

O grupo dos nutricionistas compreendeu indivíduos do sexo feminino, com idades de 26 a 50 anos, formadas entre 4 e 29 anos. Os nutricionistas atuam no ramo da cozinha entre 2 e 29 anos e exercem a posição de chefia entre 1 e 29 anos.

\section{Trajetória ocupacional}

Os trabalhadores desenvolveram outras atividades, como: ajudante de supermercado, ajudante de eletricista, ajudante de gráfica, ajudante na indústria de plástico, vigilante, ajudante de bombeiro, auxiliar de serviços gerais em empresa de transporte, ajudante de corte de roupa. No mercado informal relataram ter trabalhado como camelô, ajudante de pintor, agricultor, ajudante de pedreiro.

Observou-se que a inserção na cozinha industrial ocorreu, prioritariamente, pelo estímulo de algum conhecido (mãe, tio, irmão, colega) que 
614 F.B. KRAEMER \& O.B. AGUIAR

possuía vínculo empregatício neste setor, o que abria uma possibilidade real de conseguir uma vaga de trabalho por intermédio deste. E também pelo fato de que cozinhar parece ser uma habilidade natural de todos, já que esta tarefa é cotidianamente repetida em suas casas.

Eu vim do Norte trabalhar aqui e quando eu cheguei já entrei direto na cozinha, ai tô até hoje [...]. Um irmão meu que já trabalhava em cozinha, aí eu não tive escolha não (cozinheiro 7).

[... e eu já pelo um certo tempo procurava oportunidade em outras profissões, então é... a que de imediato surgiu foi essa. [...] como eu tive uma mãe que foi uma excelente cozinheira, então dali eu fui herdando um pouquinho dela e achei que não tinha tanto mistério. E no caso aí foi isso que me levou e me deu até um pouquinho de força prá eu entrar no ramo (cozinheiro 9).

Adicionalmente, alguns se encontravam desempregados e buscavam uma segurança de emprego, por carteira assinada ou pela oportunidade que aparecia, considerando que não faltaria emprego nesta área, já que as pessoas não vão parar de comer.

Eu entrei na profissão porque vida de camelô é muito sofrida! Um dia dá, o outro não dá. Se chover não tem como trabalhar. E eu queria arrumar um emprego de carteira assinada pra ter meu dinheirinho certo todo final do mês (cozinheiro 2).

Porque a obra caiu muito e eu resolvi vir pra um restaurante porque ninguém nunca vai parar de comer né? (cozinheiro 13).

Para os trabalhadores entrevistados, além de o trabalho se encontrar fortemente marcado pela sua dimensão de emprego, o momento de inserção no segmento encontra-se associado a uma oportunidade oferecida. Esse momento de início da vida profissional não é parte de um projeto profissional, concordando com o estudo sobre os trabalhadores de organizações públicas de saúde ${ }^{4}$, diferentemente do encontrado em um estudo da profissão médica, cujos profissionais destacam a questão da vocação e de um ideal de trabalho que orienta determinados padrões profissionais. Códigos de conduta e a valorização de um saber específico ${ }^{13}$.

Os depoimentos mencionam o início do trabalho em cozinhas, sempre a partir do cargo de Ajudante de Serviços Gerais (ASG). Este é um cargo que não exige habilidade ou escolaridade específica, assim como está vinculado a tarefas de fácil reposição operacional. A fala a seguir, chama atenção para o que eles consideram como o pior cargo que o segmento de alimentação coletiva oferece, visto que o indivíduo desenvolve as tarefas de higienização, como a limpeza geral, lavagem de louças e equipamentos, durante toda a jornada de trabalho.

Eu entrei no pior cargo da empresa! Era puxado mesmo, tinha que lavar tudo, tudo que tinha na cozinha! Era só lavar. Eu chegava 7 da manhã, ligava a bica e só desligava a bica $11 \mathrm{~h}$ da manhã para almoçar, aí voltava do almoço meio-dia e ligava a bica e ia até às 5 h, lavando tudo, dando assistência na cozinha, limpando chão (cozinheiro 2).

Pôde-se verificar que os cozinheiros iniciam sua vida profissional valorizando a possibilidade de adquirir um emprego estável. E, essa se traduz na construção de um projeto de trabalho à medida que desejam crescer. A ascensão profissional decorre da passagem de ASG para ajudante de cozinha e, posteriormente, cozinheiro. Não há uma capacitação formal para desempenhar estes cargos. O aprendizado se dá a partir da curiosidade dos trabalhadores, do interesse em aprender, da possível ascensão funcional e da observação das atividades. As oportunidades surgem na falta de um funcionário e na substituição deste pelos entrevistados.

Comecei lavando louça, depois passei a lavar chão, aí vim pro salão e depois eu 
comecei a ir pro fogão e passei para ajudante. Fui aprendendo olhando os outros fazer e conforme a minha inteligência viram que eu era capaz e me promoveram pra cozinheiro (cozinheiro 13).

O depoimento acima indica a possibilidade de os entrevistados irem assumindo funções de maior complexidade ao longo da trajetória profissional, a partir dos conhecimentos adquiridos no trabalho, sem considerar os saberes adquiridos em uma esfera formal.

\section{Qualificação e competências profissionais}

A qualificação sob a perspectiva friedmanniana, identificada também como substancialista, é centrada no saber e no saber-fazer adquiridos no trabalho e na aprendizagem sistemática ${ }^{5}$. E, é nesta perspectiva que a Classificação Brasileira de Ocupações (CBO $)^{14}$ recomenda para o exercício da ocupação do cozinheiro que o trabalhador possua Ensino Fundamental, seguido de cursos básicos de profissionalização que variam de 200 a 400 horas, ou experiência equivalente. 0 pleno desempenho das atividades ocorre entre 3 ou 4 anos de exercício profissional.

Sob a ótica substancialista da qualificação foi constatado que o percurso da maioria dos cozinheiros, conforme o demonstrado anteriormente, passa pela qualificação em serviço, é o aprender na prática do trabalho. Somente um dos entrevistados teve uma formação escolar em que realizou um curso de cozinheiro oferecido pelo Serviço Nacional de Aprendizagem Comercial (SENAC).

Em alguns processos de serviços de alimentação coletiva é consensual que o trabalhador emprega pouco conhecimento técnico-científico para o desempenho das suas atividades, e também possui um grau baixo de interação com o cliente. Este fato pode sugerir que os níveis de qualificação para os serviços de alimentação sejam, geralmente, inferiores, como afirmam Cavalli \& Salay ${ }^{12}$, e o conteúdo dos cargos pequeno. Conseqüentemente, o progresso na carreira acontece com a permanência do trabalhador na cozinha, a partir do momento que o cozinheiro adquire habilidades no desenvolvimento de novas técnicas de preparo de alimentos. Assim, a mudança de função se dá não pelo aumento da qualificação formal e sim pelo aprender a fazer (qualificação informal) e pela aquisição de competências.

Quando questionados se acham importante fazer um curso profissionalizante, todos afirmaram ser importante, pois, a partir deste poderiam crescer, ter um diploma e um dia utilizá-lo em um novo emprego.

As nutricionistas concordam com a importância da qualificação profissional dos cozinheiros, apesar de algumas não identificarem a diferença entre curso profissionalizante e curso de aperfeiçoamento. Como na maioria das Unidades de Alimentação e Nutrição os cozinheiros não possuem capacitação formal, quando questionadas do por que não os estimularem, afirmam que o fazem de acordo com orientação sobre os cursos existentes. Contudo, apesar de conhecerem as dificuldades enfrentadas pelo grupo de cozinheiros (distância do local de moradia, incompatibilidade do horário do curso com o do trabalho, cansaço), as nutricionistas, em grande parte, não viabilizam que os mesmos o façam, pois isto requereria dispensá-los de algumas atividades do trabalho.

[...] a gente sempre estimula eles, mas eles sempre reclamam que saem daqui já cansados, só se a gente liberasse eles mais cedo, que aí eles iriam fazer. Que chegam em casa muito tarde. Mas uns se interessam, mas poucos [...] aqui nenhum quis fazer [...] até o ???? outro dia comentou de um que queria sair duas horas. Como que ele vai sair duas horas? Então fica complicado (nutricionista 8).

O custo com a profissionalização é um aspecto que aparece nos discursos das nutricionistas. Há um desejo de investir, contudo não há verbas para tal. 
616 | F.B. KRAEMER \& O.B. AGUIAR

As empresas para as quais trabalham investem em cursos de aperfeiçoamento, com ênfase em controle higiênico sanitário, e alguns oferecem cursos de liderança, segurança no trabalho, manipulação de equipamentos, preparação de molhos, salgados e massas.

A idéia de projetos profissionais poderia levar a pensar que esta não faz parte das reflexões destes trabalhadores, apesar de todos gostarem do que fazem. Entretanto, alguns mencionaram o desejo de se qualificar, ilustrando uma expectativa profissional. Contudo, o maior impeditivo é a falta de condições para tal.

Se eu tivesse oportunidade, eu iria fazer técnico em nutrição. Eu tentei fazer, mas só que quando eu fui fazer, as vagas já estavam preenchidas, era até lá em Caxias. As vagas já estavam preenchidas, aí eu deixei pra lá e acabou que eu fui me acomodando e não fiz (cozinheiro 12).

Apesar da não qualificação formal os entrevistados desempenham as atividades em consonância ao estabelecido pela Classificação Brasileira de Ocupações (CBO ${ }^{14}$ para cozinheiros: organizam e supervisionam serviços de cozinha, elaborando o pré-preparo, o preparo e a finalização de alimentos, observando métodos de cocção e padrões de qualidade dos alimentos. As atividades de organização e supervisão são desenvolvidas pelos chefes de cozinha e as demais pelos cozinheiros.

A discussão da qualificação profissional remete à percepção do que é necessário para o desempenho da função: ter higiene no local de trabalho e elaborar o pré-preparo e preparo dos alimentos. Questões estas também sempre presentes no discurso das nutricionistas.

Quando questionados sobre a aprendizagem necessária para o bom exercício profissional surgiu, aliada ao conceito de qualificação, a competência profissional.

Uma parte dos trabalhadores valoriza a competência no trabalho. Para esses, o que parece contar mais no trabalho cotidiano, são algumas características pessoais e contribuições dos trabalhadores à competitividade da organização: a liderança, necessidade de agradar o cliente, de ser atencioso e propiciar um ambiente agradável, estar antenado com o mercado, acompanhar o desenvolvimento de novas tecnologias, considerar o custo e manter-se atualizado no que se refere aos cardápios que estão em voga no mercado.

O que nós fazemos aqui com carinho e dedicação e com sabor, coisa e tal, lá fora vai refletir, um vai passar pro outro: olha, a comida ali é uma delícia, o pessoal é muito atencioso, um ambiente maravilhoso. Agora se for uma comida indigesta, com muito tempero, até mesmo salgada, fica meio difícil, por isso que tem que ter atenção e evitar de errar (cozinheiro 2).

As nutricionistas também valorizam a competência no trabalho. E acrescentam que um bom cozinheiro, além das habilidades técnicas, deve ter liderança, saber se comunicar, dar sugestões de cardápios de baixo custo e saber que a alimentação tem relação com a saúde da população.

As competências determinadas por ambos, cozinheiros e nutricionistas, têm como referência o indivíduo, suas habilidades e capacidades únicas. Estão fundamentadas nas atitudes e nos comportamentos, na capacidade de antecipar os problemas.

Estes depoimentos podem ser considerados relevantes, tanto para identificação do nível de qualificação profissional dos cozinheiros quanto para a compreensão da situação do trabalho e das deficiências presentes no quadro funcional, relativas às competências, que retardam a obtenção dos macroobjetivos organizacionais.

O segmento de alimentação coletiva não foge à definição de uma empresa capitalista, mas deve ser compreendido como um espaço social cuja razão de ser é a responsabilidade com a alimentação da clientela. O conceito de alimentação coletiva está fundamentado nas leis que a ciência 
da nutrição exige para uma alimentação saudável. No mundo contemporâneo não é mais suficiente produzir refeições atraentes e saborosas. A clientela está mais atenta a uma dieta saudável e, a cada dia, cresce seu interesse pela alimentação e nutrição.

Os trabalhadores do segmento de alimentação coletiva necessitam ser inseridos nesse contexto para que as empresas de refeições coletivas apontem seus diferenciais no mercado. Para tanto a adoção da gestão de pessoas deve adotar uma estratégia coerente, que possa identificar e desenvolver em seus funcionários as competências para alcançar os propósitos organizacionais.

O estudo revelou que as competências, na maioria das vezes, ficam submersas na intensidade de atividades a serem desenvolvidas e não se articulam com os objetivos de uma Unidade de Alimentação e Nutrição. No final, a refeição está pronta, os clientes são alimentados, mas estes trabalhadores não conseguem se identificar e nem ser reconhecidos nas habilidades que Ihes são conferidas na modificação da matéria-prima.

Ao considerar que a principal fonte de diferenciação e competitividade das organizações são os recursos humanos ${ }^{15} \mathrm{e}$ que a intensa ação da concorrência impõe um novo modelo de gestão do processo produtivo, que requer aplicação de um profissional multiqualificado, espera-se uma formação que privilegie o raciocínio lógico, a abstração, o aprender a aprender, além do aprender a fazer ${ }^{16}$. As empresas que desejam investir em um crescimento e garantir o diferencial de competitividade necessário à sobrevivência da organização em uma economia globalizada devem buscar o desenvolvimento dos trabalhadores, no que tange não somente à qualificação (cursos profissionalizantes) como às competências.

As rotinas não desaparecem, mas precisam ser complementadas com uma padronização das qualificações, de forma a que possam ser tomadas as decisões correspondentes à parte não estruturada do processo. As qualificações precisam ser mais amplas, pois a competência passa a ser a capacidade tanto de seguir rotinas, quanto de tomar decisões correspondentes à parte não estruturada do processo - micro decisões.

\section{Relações interpessoais no trabalho}

Os cozinheiros trabalham com uma equipe que varia de 13 a 46 pessoas, incluindo nutricionistas, almoxarifes, auxiliares de cozinha, copeiros e ajudantes de serviços gerais. Para este trabalho a liderança foi descrita pelos entrevistados como uma competência necessária ao desempenho da função de cozinheiro.

A liderança envolve compromisso, responsabilidade, habilidade para tomada de decisões, comunicação e gerenciamento eficiente e eficaz. Sabido que as atitudes de um líder e a influência do estilo de liderança interferem no clima e nos resultados da equipe de trabalho, discutir as relações interpessoais torna-se proeminente.

Os cozinheiros e as nutricionistas relatam que não há interferência de ambos nas respectivas atividades de trabalho. É o cozinheiro que define as técnicas dietéticas empregadas e as quantidades de gêneros alimentícios utilizadas.
Graças a Deus não se mete em nada. Ela libera tudo o que eu quero fazer ela deixa eu fazer. Às vezes a gente quer trocar um prato, eu chego lá, comunico a ela, ah não, pode fazer (cozinheiro 3).
Interferir ela não interfere não, ela deixa a gente fazer as coisas, cada um sabe o que vai fazer (cozinheiro 15).

Há algumas nutricionistas que interferem no processo produtivo, discutindo o cardápio com os cozinheiros e as técnicas dietéticas adequadas.

O relacionamento com a equipe sob a supervisão dos cozinheiros foi definido como bom, embora se perceba uma contradição na fala, quando apontam problemas do cotidiano: falta dos funcionários, multiplicidade de atividades, falta de cuidado com a higiene na preparação dos alimentos. 
618 | F.B. KRAEMER \& O.B. AGUIAR

[...] o relacionamento com eles é bom [...]. Às vezes surge algum mas não é nada de grave que não possa se resolver. Ah, um funcionário doente, essa tal de licença médica, o maior problema a equipe tá completa aí um, dois pedem licença médica aí complica, vai o esquema todinho que agente tem montado dentro da carga horária, aí um tem que superar o outro, aí o problema é esse (cozinheiro 5).

Já as nutricionistas relatam alguns problemas enfrentados com os cozinheiros, como a resistência por parte dos funcionários, pois estes se sentem vigiados com a presença da nutricionista, falta de liderança, distância entre a teoria e a prática.

[...] eu deixo ele meio livre pra resolver os problemas. E a solução que ele me dá de um problema eu procuro acatar até pra valorizar a idéia dele [...] (nutricionista 2).

Apesar de as atividades dos cozinheiros serem desenvolvidas a contento, no que diz respeito às habilidades requeridas a este profissional, verifica-se uma baixa qualificação destes, assim como que a grande maioria não possui as competências necessárias identificadas por ambos os grupos de entrevistados. Ainda assim, a estes são conferidas as responsabilidades do planejamento do processo produtivo.

\section{O N C L U S Ã O}

Ao longo do trabalho procurou-se identificar a qualificação e a competência dos trabalhadores - cozinheiros, do segmento de alimentação coletiva.

Dos resultados obtidos conclui-se: 1) As Empresas de Refeições Coletivas devem repensar seu gerenciamento de pessoas, investindo na formação profissional, segundo o conceito de desenvolvimento sistemático de habilidades reunidas sob o nome de competências, e não somente no treinamento para operação; 2) Os investi- mentos em treinamento são pontuais e não têm como objetivo a qualificação formal nem o desenvolvimento de competências, restringindo-se ao cumprimento da legislação de Segurança Alimentar; 3) Tanto do ponto de vista dos nutricionistas quanto dos cozinheiros, a liderança é a principal competência necessária ao pleno desenvolvimento do trabalho destes em Unidades de Alimentação e Nutrição; 4) Para os cozinheiros, além da liderança, foram identificadas outras competências, como: agradar o cliente, ser atencioso e propiciar um ambiente aprazível, estar atento às mudanças do mercado, acompanhar o desenvolvimento de novas tecnologias, considerar o custo dos alimentos e se manter atualizado no que se refere aos cardápios que estão em voga no mercado; 5) Faz-se necessária a normalização das competências, explicitando habilidades, destrezas, compreensão e atitudes, para que as Empresas de refeição coletiva possam formalizar a certificação técnica dos trabalhadores em cozinhas industriais, de modo análogo ao que é realizado no setor industrial.

Cabe assinalar o desencontro entre as expectativas das nutricionistas e as competências que os cozinheiros têm a oferecer. Isso é particularmente importante para a formulação de propostas das competências indispensáveis a estes trabaIhadores, a fim de agregar valor à competitividade das empresas.

\section{A GRADECIMENTOS}

Ao Departamento de Extensão (Depext) da Universidade do Estado do Rio de Janeiro, pelas bolsas concedidas, e às bolsistas Raquel de Souza Mezzavilla e Renata de Carvalho Almeida, pela participação no estudo.

\section{O LABORADORES}

Ambas as autoras participaram igualmente da concepção do trabalho, da definição da metodologia, da orientação das bolsistas para a coleta de dados, da tabulação e da análise dos dados coletados, assim como da elaboração do presente artigo. 


\section{REFERÊ N CIAS}

1. Fleury MTL, Fleury A. Construindo o conceito de competência. Rev Adm Contemp. 2001; 5(Edição Especial):183-96.

2. Tartuce GLP. O que há de novo no debate da "qualificação do trabalho"? Reflexões sobre o conceito com base nas obras de Georges Friedmann e Pierre Naville [mestrado]. São Paulo: Universidade de São Paulo; 2002.

3. Santana MA, Ramalho JR. Sociologia do trabalho no mundo contemporâneo. Rio de Janeiro: Jorge Zahar; 2004.

4. Vieira M. Trabalho, qualificação e a construção social de identidades profissionais nas organizações públicas de saúde. Trab Educ Saúde. [periódico na internet]. 2007 [acesso 2008 maio 27]; 5(2):243-60. Disponível em: <http://www. revista.epsjv.fiocruz. br//include/mostrarpdf. cfm?Num=169>.

5. Laudares JB, Tomasi A. O técnico de escolaridade média no setor produtivo: seu novo lugar e suas competências. Educ Soc. [periódico da internet]. 2003 [acesso 2008 maio 22]; 24(85):1237-1256. Disponível em: <http://www.cedes.unicamp.br>. doi: 10.1590/S0101-73302003000400007.

6. Proença RPC. Novas tecnologias para a produção de refeições coletivas: recomendações de introdução para a realidade brasileira. Rev Nutr. 1999; 12(1):43-53. doi:10.1590/S1415-5231999000 100004.

7. Lanzillotti HS. Contribuição ao estudo da alimentação coletiva no capitalismo fordista [doutorado]. Rio de Janeiro: Universidade do Estado do Rio de Janeiro; 2000.
8. Manfredi SM. Work, qualification and professional skill - political and conceptual dimensions. Educ Soc. [periódico na internet]. 1998 [acesso 2008 maio 22]; 19(64). Disponível em: <http://www. scielo.br/scielo.php?script=sci_arttext\&pid= S0101-73301998000300002\&lng=en\&nrm= iso>. doi: 10.1590/S0101-73301998000300002.

9. Godoy AS. Introdução à pesquisa qualitativa e suas possibilidades. Rev Adm Emp. 1995; 35 (2):57-63.

10. Minayo MCS. O desafio do conhecimento: pesquisa qualitativa em saúde. São Paulo: Hucitec; 1992.

11. Richardson RJ. Pesquisa social. 3a. ed. São Paulo: Atlas; 1999.

12. Cavalli SB, Salay E. Gestão de pessoas em unidades produtoras de refeições comerciais e a segurança alimentar. Rev Nutr. 2007; 20(6):657-67. doi: 10.1590/S1415-52732007000600008.

13. Vieira M. Infectologistas e Aids: novas dimensões da prática [mestrado]. Rio de Janeiro: Fiocruz; 1996.

14. Brasil. Ministério do Trabalho e Emprego. Classificação Brasileira de Ocupações. Brasília: 2002 [acesso 1 abr 2002]. Disponível em: <http://www. mtecbo.gov.br/busca.asp>.

15. Germano MIS. Treinamento de manipuladores de alimentos: fator de segurança alimentar e promoção da saúde. São Paulo: Livraria Varela; 2003.

16. Pereira CS, Coutinho MTC, Johann SL, Rocha-Pinto, SR. Dimensões funcionais da gestão de pessoas. Rio de janeiro: FGV; 2003.

Recebido em: 6/8/2007

Versão final reapresentada em: 13/4/2009

Aprovado em: 7/7/2009 